\title{
A Rapid Preconcentration Method Using Modified GP-MSE for Sensitive Determina- tion of Trace Semivolatile Organic Pollutants in the Gas Phase of Ambient Air
}

\author{
Miao He, Qingjuan Xu, Cui Yang, Xiangfan Piao, ${ }^{*}$ Narayanan Kannan, ${ }^{\dagger}$ and Donghao $\mathrm{Li}^{*}$ \\ Key Laboratory of Natural Resource of the Changbai Mountain and Functional Molecular, Ministry of Education, \\ Yanbian University, Park Road 977, Yanji City, Jilin Province 133002, China \\ *E-mail:dhli@ybu.edu.cn (D.Li); pxf@ybu.edu.cn (X. Piao) \\ ${ }^{\dagger}$ Faculty of Environmental Studies, Universiti Putra Malaysia, 43400 UPM Serdang, Selangor Darul Ehsan, Malaysia \\ Received March 13, 2014, Accepted June 16, 2014
}

\begin{abstract}
A sensitive concentration method utilising modified gas-purge microsyringe extraction (GP-MSE) was developed. Concentration (reduction in volume) to a microlitre volume was achieved. PAHs were utilised as semivolatile analytes to optimise the various parameters that affect the concentration efficiency. The injection rate and temperature were the key factors that affected the concentration efficiency. An efficient concentration (75.0-96.1\%) of PAHs was obtained under the optimised conditions. The method exhibited good reproducibility (RSD values that ranged from 1.5 to $9.0 \%$ ). The GP-MSE concentration method enhances the volume reduction (concentration factor), leading to a low method detection limit $\left(0.5-15 \mathrm{ng} \mathrm{L}^{-1}\right)$. Furthermore, this method offers the advantage of small-volume sampling, enabling even the detection of diurnal hourly changes in the concentration of PAHs in ambient air. Utilising this method in combination with GC-MS, the diurnal hourly flux of PAHs from the gas phase of ambient air was measured. Indeed, the proposed technique is a simple, fast, low-cost and environmentally friendly.
\end{abstract}

Key Words : Gas purge, Microextraction, Concentration, Atmospheric, Trace pollutants

\section{Introduction}

The development of sample pretreatment techniques for environmental analysis has been the subject of much researchers. ${ }^{1-3}$ Although certain organic pollutants in the environment occur at trace levels, they can seriously threaten human health, either directly or indirectly, due to their toxicity and bioaccumulation. Therefore, the detection of trace environmental organic pollutants is necessary. The analysis of trace levels of organic pollutants in the environment by chromatographic techniques presents a great challenge due to their low detectability by instrumental analysis. Additionally, matrix interference can be a problem as well. ${ }^{4-6}$ Conventional pretreatment techniques require large sample sizes/volumes, which in turn require large amounts of time and energy to process. The detection of PAHs in the gas phase in the atmosphere represents a classical problem in this context. ${ }^{7-9}$ The analysis of trace semivolatile compounds usually requires the extraction of analytes from a sample matrix, followed by concentration (volume reduction) prior to analysis for better detectability in chromatographic techniques. ${ }^{10,11}$ Many studies have been dedicated to the improvement of the extraction and cleanup of these compounds, but only a few have focused on the improvement of the concentration of analytes. ${ }^{12,13}$ It is very important to enhance the concentration factor because doing so will improve the detectability of target compounds, allowing for small sample sizes and short analytical times.

Conventional concentration methods are based on volume reduction by the evaporation of the solvent that contains the analytes. Inert gas streams are routinely used in laboratories. $^{14,15}$ A common procedure is to blow an inert gas stream onto the surface of the solvent (extract). The more volatile solvents are removed, and the less volatile analytes are retained, which concentrates them. The rate of evaporation may be increased by heating, which accelerates the concentration process. Rotary evaporators are also used routinely in laboratories, utilising a water bath as the heat source. ${ }^{16,17}$ These evaporation techniques can only achieve millilitre-level volume reductions; thus, further requires microconcentration is required to suit instrumental analysis.

In recent years, many reports on new concentration techniques such as the hollow-fibre membrane pervaporation technique have been published. ${ }^{18,19}$ Pervaporation is an effective separation method utilising membrane permeation and evaporation. ${ }^{20}$ The hollow-fibre membrane pervaporation technique shows a low efficiency for semivolatile compounds and could be "environmentally unfriendly" because the volatilised solvent escapes to the atmosphere. A purge-andtrap concentrator has also been commercialised, having been pioneered by Bellar and Lichtenberg in 1974. Many researchers have developed several methods based on the purge-and-trap technique. ${ }^{21,22}$ Despite the method's sensitivity and reliability, the operation of these methods is complex, and serious foaming and clogging of the gas easily occur. Moreover, the methods are more suitable for the detection of volatile compounds. ${ }^{23,24}$

Gas-purge microsyringe extraction (GP-MSE) is a novel sample pretreatment technology developed by Yang et al., ${ }^{25}$ that has been patented. ${ }^{26}$ The features of this technique are 
integration and miniaturisation. GP-MSE represents the most effective procedure for the extraction and preconcentration of analytes. This technology was developed from gasflow headspace liquid-phase microextraction (GF-HS-LPME), which is based on liquid-phase microextraction (LPME). ${ }^{27}$ GP-MSE is an exhaustive extraction technique, and it is much faster ( $3 \mathrm{~min}$ ) than existing methods, environmentally friendly, simple to operate, economical and demonstrated to have high extraction efficiency for volatile compounds and semivolatile chemicals. ${ }^{27}$

An attempt was made in this study to develop a sensitive concentration method modelled after GP-MSE that can concentrate extracts to the microlitre level and greatly reduce the required sample volume. PAHs were selected as representative semivolatile analytes, and various parameters that affect the concentration efficiency, such as the temperature, the sample-injection rate and the nitrogen-flow rate, were optimised. Finally, an attempt was made to measure the diurnal hourly flux of PAHs in the gas phase of ambient air using this method.

\section{Experimental Section}

Material and Methods. The standard mixture used in this study contained sixteen PAHs: naphthalene (Nap), acenaphthylene (Acp), acenaphthene (Ace), fluorine (Flu), phenanthrene (Phe), anthracene (Anth), fluoranthene (Fluo), pyrene (Pyr), benzo $[a]$ anthracene $(\mathrm{B}[a] \mathrm{A})$, chrysene $(\mathrm{Chr})$, benzo $[b]$ fluoranthene $(\mathrm{B}[b] \mathrm{F})$, benzo $[k]$ fluoranthene $(\mathrm{B}[k] \mathrm{F})$, benzo $[a]$ pyrene $(\mathrm{B}[a] \mathrm{P})$, indeno[1,2,3-cd]pyrene (InP), dibenzo[a,h]anthracene (DBA), and benzo[ghi]perylene (BghiP). An internal standard $\left(\left[{ }^{2} \mathrm{H}_{10}\right]\right.$ phenanthrene) and a surrogate standard $\left(\left[{ }^{2} \mathrm{H}_{10}\right]\right.$ acenaphthene and $\left[{ }^{2} \mathrm{H}_{12}\right]$ perylene) were purchased from Supelco (Bellefonte, PA, USA). The purity of the standards was generally higher than $99 \%$. HPLC-grade dichloromethane was obtained from Caledon
(Georgetown, Ont., Canada). Stock standard solutions of the PAHs $\left(20 \mathrm{mg} \mathrm{L}^{-1}\right)$ were prepared in methanol and were diluted to $20 \mu \mathrm{g} \mathrm{L}^{-1}$ with dichloromethane. Standard working solutions of various concentrations were prepared by diluting the stock solutions with dichloromethane. The internal standard was spiked into dichloromethane $(400 \mu \mathrm{g}$ $\mathrm{L}^{-1}$ ) when it was used as an extracting solvent. The surrogate standard was also spiked into dichloromethane $\left(200 \mu \mathrm{g} \mathrm{L}^{-1}\right)$. The standard solutions and the extracting solvent were stored in the dark at $0-4{ }^{\circ} \mathrm{C}$ until use. The purity of the nitrogen $\left(\mathrm{N}_{2}\right)$ used as a flow gas was $99.999 \%$. A single-channel syringe pump (KDS100), made in the USA, was purchased from Shenzhen.

Sample Collection and Preparation. The level of PAHs in the gas phase in ambient air was determined by collecting air in the gas-flow liquid-phase enrichment apparatus (GFLPE) developed previously by our group (see Figure S1 in the supplementary information). The sampling site was Yanji City, where Yanbian University is located. The air sampling rate was $0.530 \mathrm{~L} \mathrm{~min}^{-1}$, and the sampling time was $4 \mathrm{~h}$. The gas was pumped into the gas absorber through a flow meter, and the organic compounds were absorbed in $100 \mathrm{~mL}$ dichloromethane. After sampling, the surrogate standard was spiked into the sample $\left(20 \mathrm{ng} \mathrm{L}^{-1}\right)$ and then concentrated to 1 $\mathrm{mL}$ by conventional techniques and further tested by GPMSE. These experiments have already been standardised in our laboratory.

GP-MSE Concentration Apparatus and Procedure. Please refer to Yang et $a l^{25,27}$ for a description of the GPMSE concentration apparatus. It should by noted, however, that the version used in this experiment is slightly different from the original, as explained in Figure 1. The sampleinjection port and the solvent recovery port were enlarged. The sample-injection port included a syringe pump, a microsyringe $(1 \mathrm{~mL})$ and a PTFE tube (O.D.: $1.5 \mathrm{~mm}$; I.D.: $0.75 \mathrm{~mm}$; length: $10 \mathrm{~cm})$. The solvent-recovering section
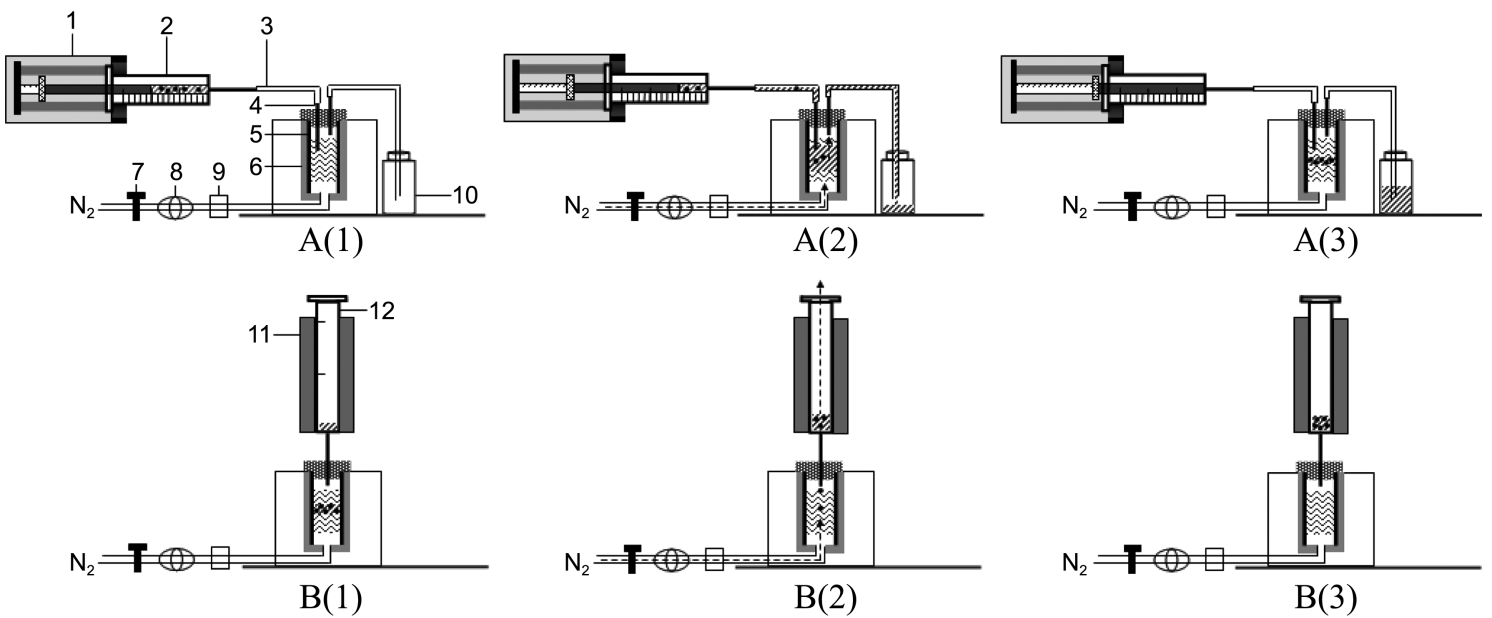

Figure 1. Schematic diagram of the modified GPMSE apparatus. $A(1), A(2), A(3)$ represent the concentration process; $B(1)$, $B(2)$, $B(3)$ represent the absorption process. denotes the target compound; the grey slash represents the organic solvent; the dotted line represents the gas-flow pathway; and the wavy curve represents glass wool. The numbers indicate the following: 1 , syringe pump; 2 , microsyringe (1 mL); 3, PTFE tube; 4, needle; 5, sample cell; 6, heat chamber; 7, T-value; 8, gas-flow controller; 9, digital monitor; 10, waste vial; 11, cooler; and 12, microsyringe barrel $(100 \mu \mathrm{L})$. 
featured a waste vial and a PTFE tube. The PTFE tubes in the two sections were connected with a single microsyringe needle and matched to each other. A microsyringe $(1 \mathrm{~mL})$ was used to inject the sample into the sample cell by the syringe pump, and a waste vial was used to collect the volatilised solvent.

The concentrating process is explained in Figure 1(a). The process consists of the following steps. (1) A sample cell was placed into the heat chamber, and then the heat chamber was sealed with a PTFE septum. The two PTFE tubes, one connected to the microsyringe $(1 \mathrm{~mL})$ and the other connected to the waste vial, were carefully inserted into the chamber via the septum. (2) The temperature of the chamber and the nitrogen flow were set to $80^{\circ} \mathrm{C}$ and $2.0 \mathrm{~mL} \mathrm{~min}{ }^{-1}$, respectively. The $0.5 \mathrm{~mL}$ sample solution (solvent and analytes) loaded in the microsyringe $(1 \mathrm{~mL})$ was continuously injected into the sample cell at an injection rate of 167 $\mu \mathrm{L} \min ^{-1}$, and then the concentration process was initiated. Upon injection, the solvent and the analytes in the sample were separated due to their dissimilar volatilities. It is noted that the sample cell should always be moist during this process. At a relatively low temperature, the solvent was volatilised easily due to its low boiling point and was carried away by the nitrogen flow into the waste vial. The analytes were retained in the sample cell during this process due to their relatively low volatility. (3) When the sample was completely injected, all of the parameters of the GP-MSE were shut down. In this concentration procedure, only the analytes and a few microlitres of solvent remained in the sample cell, and almost all of the evaporated solvent was recovered in the waste vial.

The extraction process is explained in Figure 1(b). The process consists of the following steps. (1) The PTFE tubes were pulled out, followed by the insertion of a $100 \mu \mathrm{L}$ microsyringe barrel (without the plunger) into the chamber through the septum. (2) The GP-MSE parameters were reset as follows. The temperature of the heat chamber was $280^{\circ} \mathrm{C}$, the extraction time was $3 \mathrm{~min}$, the nitrogen-flow rate was 2.0 $\mathrm{mL} \min ^{-1}$ and the cooler temperature was $-4^{\circ} \mathrm{C}$. A $5 \mu \mathrm{L}$ volume of extracting solvent was added to the $100 \mu \mathrm{L}$ microsyringe barrel, and then the extraction was initiated. A similar operating principle and practical result were observed by Yang et al. ${ }^{25-27}$ : briefly, at a high extraction temperature, the analytes and a few microlitres of solvent in the sample cell were volatilised and carried away by the nitrogen flow, and they were absorbed by extraction of the solvent in the microsyringe barrel. (3) After extraction ( $3 \mathrm{~min}$ ), the analytes were quantitatively absorbed by the extracting solvent. The microsyringe barrel was removed from the apparatus, and the extract was directly analysed by GC-MS.

Analytical Methods. Chromatographic analysis was performed by a Shimadzu GC 2010 with a DB5 fused-silica capillary column $(30 \mathrm{~m} \times 0.25 \mathrm{~mm}$; thickness: $0.25 \mu \mathrm{m})$ and detected on a Shimadzu QPMS 2010 mass spectrometer with a quadrupole mass-spectrometer system. The injection temperature was $280^{\circ} \mathrm{C}$ in the splitless mode, and the interface temperature was set to $280{ }^{\circ} \mathrm{C}$. The column temperature was maintained at $80^{\circ} \mathrm{C}$ for 2 min, and then it was programmed to increase by $20^{\circ} \mathrm{C} \mathrm{min}^{-1}$ to $100^{\circ} \mathrm{C}$ and then by $10{ }^{\circ} \mathrm{C} \mathrm{min}^{-1}$ to $280{ }^{\circ} \mathrm{C}$; it was then held at this latter temperature for $21 \mathrm{~min}$. The column flow was $1.20 \mathrm{~mL} \mathrm{~min}^{-1}$. Helium (99.999\% pure) was used as a carrier gas. The electron ionisation selected ion mode (EI-SIM) was used for quantification of the analytes. The solvent-cut time was $5.0 \mathrm{~min}$. The ion-source temperature and the energy of the ionising electrons were set to $200^{\circ} \mathrm{C}$ and $70 \mathrm{eV}$, respectively.

Calculation. To optimise the various parameters, the preconcentration efficiency and concentration factor were calculated.

The preconcentration efficiency (CE) is defined as follows:

$$
\mathrm{CE}=\mathrm{n}_{\mathrm{i}} / \mathrm{n}_{0}=\mathrm{C}_{\mathrm{i}} \mathrm{V}_{\mathrm{i}} / \mathrm{C}_{0} \mathrm{~V}_{0},
$$

where $n_{i}$ and $n_{0}$ are the analyte masses in the final extract after GP-MSE concentration and in the sample, respectively; $\mathrm{C}_{\mathrm{i}}$ and $\mathrm{C}_{0}$ are the analyte concentrations in the final extract after GP-MSE concentration and in the sample, respectively; and $\mathrm{V}_{\mathrm{i}}$ and $\mathrm{V}_{0}$ are the volume of the extract after GP-MSE concentration and that of the original sample, respectively.

The concentration factor (CF) was defined as the ratio of the concentration of the analytes in the final extract after GPMSE concentration to that in the original sample and is expressed as follows: $\mathrm{CF}=\mathrm{C}_{\mathrm{i}} / \mathrm{C}_{0}$.

\section{Results and Discussion}

Optimization Parameters of GP-MSE Concentration. During the preconcentration process, the sample solution in the microsyringe was continuously injected into the sample cell by a syringe pump at a certain rate while the evaporated solvent was carried away by a gentle nitrogen flow when the temperature at which the concentration was performed (hereafter referred to as the "concentration temperature") was relatively low. The analytes are retained in the sample cell during this process due to their relatively low volatility. Thus, the main parameters that affect the preconcentration efficiency are the sample-injection rate, the concentration temperature and the nitrogen-flow rate. To determine the effects of these parameters, $0.5 \mathrm{~mL}$ stock solutions of standard PAHs $\left(4 \mu \mathrm{g} \mathrm{L}^{-1}\right)$ were tested, and the results were calculated for six different PAHs.

The Evaporation Rate of the Solvent in the GP-MSE Concentration Process. It is well known that the target analytes will lose, if there is no solvent,. Maintaining moist conditions for the sample cell during the concentration process is very important for the preconcentration efficiency because the analytes must be absorbed in a solvent medium. First, we determined the evaporation rates of dichloromethane in the GP-MSE concentration process at various temperatures: $50 \mu \mathrm{L} \mathrm{min}{ }^{-1}, 117 \mu \mathrm{L} \mathrm{min}^{-1}$ and $150 \mu \mathrm{L} \mathrm{min}^{-1}$ at $50{ }^{\circ} \mathrm{C}, 70^{\circ} \mathrm{C}$ and $80^{\circ} \mathrm{C}$, respectively. Clearly, at high temperature, faster evaporation occurs (see Figure S2 in the supplementary information), but higher temperature not investigated in order to make the control is convenient in the experiment process, and ensure good repeatability. 


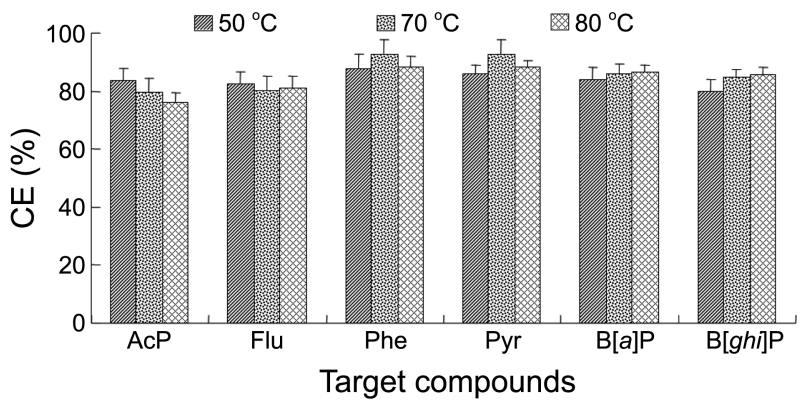

Figure 2. Concentration efficiency (CE) plotted as a function of concentration temperature. The experimental conditions were as follows. Initial volume: $0.5 \mathrm{~mL}$; initial concentration: $4 \mu \mathrm{g} \mathrm{L}^{-1}$; final volume: $10 \mu \mathrm{L}$; and $\mathrm{N}_{2}$-flow rate: $2.0 \mathrm{~mL} \mathrm{~min}^{-1}$. At $50{ }^{\circ} \mathrm{C}$, $70{ }^{\circ} \mathrm{C}$ and $80^{\circ} \mathrm{C}$, the injection rates were $67 \mu \mathrm{L} \mathrm{min}{ }^{-1}, 133 \mu \mathrm{L}$ $\min ^{-1}$ and $167 \mu \mathrm{L} \mathrm{m^{-1 }}$, respectively.

Optimisation of the Concentration Temperature. We evaluated the effect of temperature on the preconcentration efficiency at $50^{\circ} \mathrm{C}, 70^{\circ} \mathrm{C}$ and $80^{\circ} \mathrm{C}$, respectively. The optimisation results are shown in Figure 2. The preconcentration efficiency (CE) is plotted as a function of the concentration temperature. All of the selected injection rates were slightly higher than the evaporation rate of the solvent during the GP-MSE concentration process. At $50^{\circ} \mathrm{C}, 70^{\circ} \mathrm{C}$ and $80^{\circ} \mathrm{C}$, we chose injection rates of $67 \mu \mathrm{L} \mathrm{min}^{-1}, 133 \mu \mathrm{L} \mathrm{min}^{-1}$ and $167 \mu \mathrm{L} \mathrm{min}{ }^{-1}$, respectively. The sample cell was kept moist during the entire concentration process. It was determined that the temperature variation had no significant effect on the concentration efficiency. The concentration time was reduced as the temperature was increased. At $80^{\circ} \mathrm{C}$, the concentration time was the shortest: only 3 min plus the extraction time was required. Thus, $80^{\circ} \mathrm{C}$ was set as the operating temperature in the standardised procedure in order to achieve of rapid extraction.

Optimisation of the Sample-injection Rate. Next, we evaluated the preconcentration efficiency at various sampleinjection rates. The results are shown in Figure 3. We selected three injection rates, namely $133 \mu \mathrm{L} \mathrm{min}^{-1}, 167 \mu \mathrm{L} \mathrm{min}^{-1}$ and $200 \mu \mathrm{L} \mathrm{min}^{-1}$, at $80^{\circ} \mathrm{C}$. At an excessively low injection rate the loss of the low-boiling-point analytes was high, but no effect was observed for the high-boiling-point compounds. The probable reason for this effect is that the evaporation of the solvent is rapid, making the cell dry and causing the lowboiling-point analytes to be lost at a slow injection rate. However, when the sample-injection rate was higher than the solvent-evaporation rate, then the sample cell was kept wet, and the low-boiling-point analytes were kept in the chamber due to the moist conditions. However, when the injection rate was too fast, the sample cell was overloaded, leading to a downward flow of sample into the gas pipe. As a result, all of the analytes showed significant loss. Therefore, the injection rate of the sample must be higher than the evaporation rate of the solvent; in other words, the sample cell must be kept moist throughout the entire process to prevent the loss of analytes.

Optimisation of the $\mathbf{N}_{2}$-flow Rate. In the GP-MSE pre-

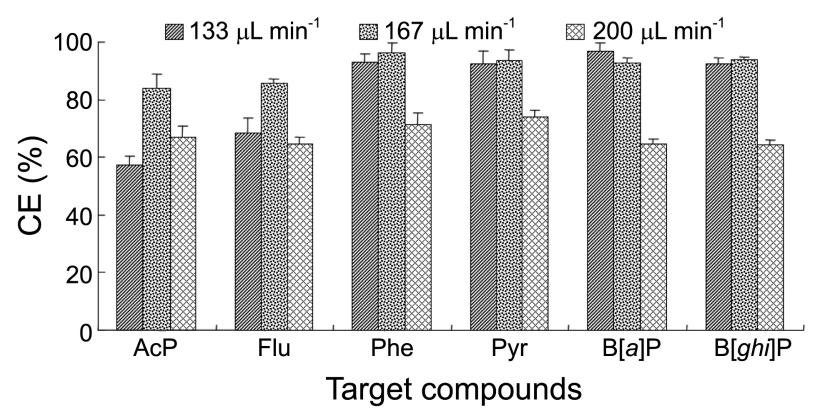

Figure 3. Concentration efficiency (CE) plotted as a function of the injection rate. The experimental conditions were as follows. Initial volume: $0.5 \mathrm{~mL}$; initial concentration: $4 \mu \mathrm{g} \mathrm{L}{ }^{-1}$; final volume: $10 \mu \mathrm{L}$; concentration temperature: $80^{\circ} \mathrm{C}$; and $\mathrm{N}_{2}$-flow rate: $2.0 \mathrm{~mL} \mathrm{~min}^{-1}$.

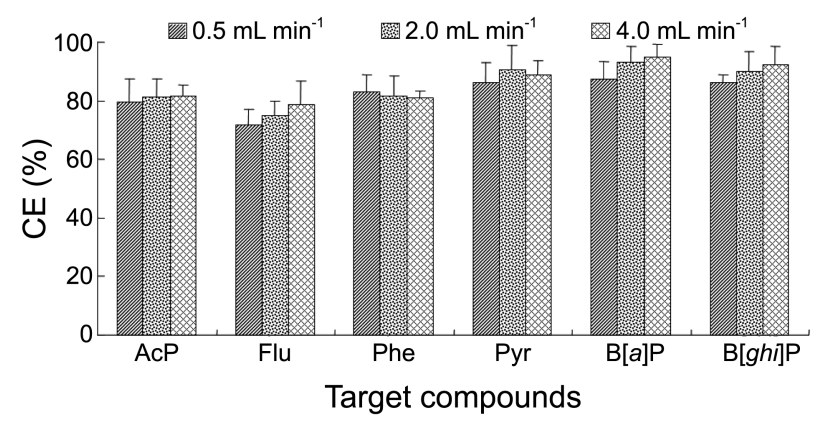

Figure 4. Concentration efficiency (CE) plotted as a function of the flow rate of $\mathrm{N}_{2}$. The experimental conditions were as follows. Initial volume: $0.5 \mathrm{~mL}$; initial concentration: $4 \mu \mathrm{g} \mathrm{L}{ }^{-1}$; final volume: $10 \mu \mathrm{L}$; concentration temperature: $80^{\circ} \mathrm{C}$; and injection

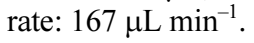

concentration technique, the solvent is evaporated from the extract (sample matrix), and then it is carried by the gentle inert-gas stream to the waste vial. To understand the effect of the gas-flow rate on the concentration efficiency, the gasflow rates were fixed at $0.5,2.0$ and $4.0 \mathrm{~mL} \mathrm{~min}^{-1}(0.5$ and $4.0 \mathrm{~mL} \mathrm{~min}{ }^{-1}$ were the minimum and the maximum rates of the gas mass-flow controller unit, respectively), and then the results were compared as shown in Figure 4. The concentration efficiency remained nearly unchanged at the varying gas-flow rates because the gentle gas flow did not change the moist state of the sample cell. A gas-flow rate of $2.0 \mathrm{~mL}$ $\mathrm{min}^{-1}$ was fixed as the standard flow rate in the remainder of the experiment.

Evaluation of the Method Performance. A standard mixture of PAHs was used to evaluate the method detection limit (MDL), reproducibility and linearity of the proposed thechnique. The MDL ranged from 0.5 to $15 \mathrm{ng} \mathrm{L}^{-1}$ (three times the signal-to-noise ratio). The reproducibility was indicated by the relative standard deviation (RSD) for a standard mixture of PAHs at the $4 \mu \mathrm{g} \mathrm{L}^{-1}$ level. The proposed method exhibited good reproducibility, with RSD values ranging from 1.5 to $9.0 \%$ for three repetitions. To investigate the linearity of the method by experimentation, five different concentrations $\left(0.2,0.4,1,5\right.$ and $\left.20 \mu \mathrm{g} \mathrm{L}^{-1}\right)$ of the standard mixture of PAHs were used. Good linearity was 
Table 1. The analytical characteristics of GP-MSE concentration method

\begin{tabular}{ccccc}
\hline Compound & $\begin{array}{c}\text { MDL } \\
(\mathrm{pg})\end{array}$ & $\begin{array}{c}\text { Linearity } \\
\left(\mathrm{r}^{2}\right)\end{array}$ & $\begin{array}{c}\text { RSD (\%) } \\
(\mathrm{n}=6)\end{array}$ & CE (\%) \\
\hline Nap & 0.5 & 0.9905 & 8.2 & 75.0 \\
AcPy & 0.5 & 0.9926 & 5.3 & 77.7 \\
AcP & 0.5 & 0.9910 & 5.5 & 83.9 \\
Flu & 0.5 & 0.9947 & 6.0 & 85.9 \\
Phe & 0.5 & 0.9967 & 6.5 & 96.1 \\
AnT & 0.5 & 0.9963 & 1.6 & 89.3 \\
FluA & 0.5 & 0.9960 & 5.0 & 96.0 \\
Pyr & 0.5 & 0.9966 & 1.5 & 95.0 \\
B[a]A & 1.0 & 0.9995 & 5.5 & 99.3 \\
Chr & 1.0 & 0.9981 & 5.8 & 94.6 \\
B[b]F & 1.0 & 0.9988 & 4.9 & 91.0 \\
B $[k] \mathrm{F}$ & 1.0 & 0.9911 & 7.1 & 88.1 \\
B[a]P & 1.5 & 0.9993 & 4.5 & 82.7 \\
IND & 15 & 0.9975 & 9.0 & 81.3 \\
DBA & 15 & 0.9994 & 8.2 & 82.2 \\
B[ghi]P & 15 & 0.9993 & 6.3 & 83.7 \\
\hline
\end{tabular}

Abbreviations: $\mathrm{MDL}=$ method detection limit (three times of the signalto-noise ratio); Nap = naphthalene; AcPy = acenaphthylene; AcP = acenaphthene; $\mathrm{Flu}=$ fluorene; $\mathrm{Phe}=$ phenanthrene; AnT = anthracene; FluA = fluoranthene; $\mathrm{Pyr}=$ pyrene; $\mathrm{B}[a] \mathrm{A}=$ beazo $[a]$ anthracee; $\mathrm{Chr}=$ chrysene; $\mathrm{B}[b] \mathrm{F}=$ beazo $[b]$ fluoranthene; $\mathrm{B}[k] \mathrm{F}=$ beazo $[k]$ fluoranthene; $\mathrm{B}[a] \mathrm{P}=$ beazo $[a]$ pyrene; $\mathrm{IND}=$ indeno[1,2,3-cd $]$ pyrene; $\mathrm{DBA}=$ dibenz$[a, h]$ anthracene; $\mathrm{B}[g h i] \mathrm{P}=$ benzo $[g h i]$ perylene.

obtained at all five concentrations, with the correlation coefficient $\left(\mathrm{R}^{2}\right)$ ranging from 0.9905 to 0.9995 . The concentration efficiency was determined under the optimised conditions of $80^{\circ} \mathrm{C}, 167 \mu \mathrm{L} \mathrm{min}^{-1}$ (injection rate) and $2.0 \mathrm{~mL} \mathrm{~min}^{-1}$ (gas-flow rate). The concentration efficiency for the $4 \mu \mathrm{g} \mathrm{L}^{-1}$ standard mixtures ranged from 75.0 to $96.1 \%$. The results are summarised in Table 1.

Application. The presence of PAHs in the gas phase of ambient air was determined by the proposed method. First, the results obtained from the GP-MSE preconcentration were compared with those obtained from the conventional concentration method (using a nitrogen blow-down device). Eight PAHs were detected in the gas phase of the atmospheric sample, and the concentrations were 445.1, 12.3, $63.5,227.3,383.8,29.0,38.7$ and $25.1 \mathrm{ng} \mathrm{m}^{-3}$ for naphthalene, acenaphthylene, acenaphthene, fluorene, phenanthrene, anthracene, fluoranthene and pyrene, respectively, as deter- mined by GP-MSE preconcentration (the recoveries of the surrogate standards ranged from $86.8 \%$ to $92.3 \%$ ). The fact that the results of the GP-MSE preconcentration were similar to the results obtained using a conventional nitrogen blowdown device confirmed the reliability of the new method. The concentration factor for GP-MSE was much higher than that for the conventional techniques by up to six orders of magnitude (Table 2).

Additionally, we used the proposed method to analyse the diurnal hourly concentration flux of PAHs in the gas phase of ambient air. The PAH concentrations in the gas phase are listed in Table 3. The eight PAHs naphthalene, acenaphthylene, acenaphthene, fluorene, phenanthrene, anthracene, fluoranthene and pyrene were detected, and their concentrations ranged from 4.3 to $177.7 \mathrm{ng} \mathrm{m}^{-3}$ (the recoveries of the surrogate standards ranged from $88.0 \%$ to $94.5 \%$ ). The concentrations of naphthalene, fluorene and phenanthrene were higher than those of the other molecules. The PAH concentrations in the gas phase of the atmospheric sample were at the ultra-trace level; thus, traditional methods would require a large sample volume for instrumental detectability. The GP-MSE preconcentration method showed high sensitivity, by which it was possible to detect the diurnal hourly concentration of PAHs in the gaseous phase of the ambient air.

\section{Conclusion}

GP-MSE preconcentration is a sensitive sample-pretreatment method that exhibits excellent analytical performance for the determination of trace semivolatile organic pollutants. A high concentration efficiency was achieved when the injection rate and the temperature were adjusted appropriately and the sample cell was kept moist during the concentration process. The GP-MSE preconcentration method achieved a microlitre-level reduction and greatly reduced the initial sampling volume. The diurnal hourly flux of PAHs in the gas phase of ambient air was determined by this method, which holds good prospects for the detection of trace- to ultra-trace-level semivolatile organic pollutants in the environment using relatively small sample volumes.

Acknowledgments. This study was supported by a grant from the National Natural Science Foundation of China (No. 21165020, 21265023).

Table 2. Comparison of the detection of PAHs in the gas phase of ambient air by the proposed method compared with that by two other concentration methods

\begin{tabular}{|c|c|c|c|c|c|c|c|c|}
\hline & \multicolumn{8}{|c|}{ Concentration $\left(\mathrm{ng} \mathrm{m}^{-3}\right)$} \\
\hline & Nap & Acp & Ace & Flu & Phe & Anth & Fluo & Pyr \\
\hline GP-MSE & 445.1 & 12.3 & 63.5 & 227.3 & 383.8 & 29.0 & 38.7 & 25.1 \\
\hline Conventional $^{a}$ & 450.5 & 13.5 & 60.6 & 223.5 & 376.8 & 30.7 & 38.9 & 26.2 \\
\hline $\mathrm{CF}^{b}$ & \multicolumn{8}{|c|}{$3.18 \times 10^{6}$} \\
\hline $\mathrm{CF}^{c}$ & \multicolumn{8}{|c|}{$6.36 \times 10^{4}$} \\
\hline
\end{tabular}

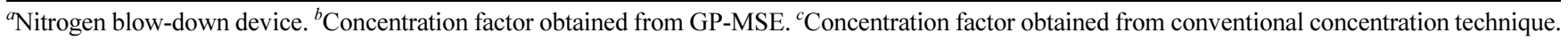


Table 3. Diurnal hourly concentrations of PAHs in the gas phase of ambient air

\begin{tabular}{|c|c|c|c|c|c|c|c|c|}
\hline \multirow{2}{*}{ Sampling time } & \multicolumn{8}{|c|}{ Concentration $\left(\mathrm{ng} \mathrm{m}^{-3}\right)$} \\
\hline & Nap & Acp & Ace & Flu & Phe & Anth & Fluo & Pyr \\
\hline 00:00-1:00 & 132.9 & 7.0 & 21.2 & 59.1 & 148.4 & 10.2 & 18.1 & 8.8 \\
\hline $1: 00-2: 00$ & 155.0 & 12.6 & 37.7 & 70.5 & 126.4 & 9.8 & 14.0 & 7.2 \\
\hline $2: 00-3: 00$ & 143.1 & 12.9 & 28.7 & 68.9 & 147.3 & 10.1 & 17.7 & 8.5 \\
\hline $3: 00-4: 00$ & 101.1 & 7.7 & 20.4 & 43.7 & 76.9 & 6.0 & 7.3 & 4.7 \\
\hline $4: 00-5: 00$ & 96.5 & 7.5 & 17.0 & 40.0 & 74.6 & 5.4 & 6.8 & 6.0 \\
\hline $5: 00-6: 00$ & 58.0 & 7.3 & 18.9 & 46.5 & 109.8 & 9.2 & 10.5 & 5.1 \\
\hline $6: 00-7: 00$ & 90.3 & 7.8 & 22.1 & 55.5 & 126.1 & 8.5 & 14.1 & 7.0 \\
\hline $7: 00-8: 00$ & 125.3 & 12.5 & 31.8 & 88.7 & 195.6 & 17.1 & 22.5 & 11.7 \\
\hline $8: 00-9: 00$ & 54.2 & 11.2 & 26.3 & 85.9 & 172.1 & 11.6 & 16.9 & 8.9 \\
\hline $9: 00-10: 00$ & 97.2 & 9.1 & 17.7 & 43.3 & 100.0 & 7.1 & 10.0 & 6.0 \\
\hline $10: 00-11: 00$ & 136.3 & 12.6 & 32.3 & 86.8 & 177.7 & 12.1 & 15.1 & 9.7 \\
\hline $11: 00-12: 00$ & 169.4 & 15.4 & 38.4 & 98.4 & 212.1 & 13.4 & 17.8 & 9.8 \\
\hline $12: 00-13: 00$ & 50.2 & 4.8 & 12.2 & 33.8 & 81.8 & 7.4 & 8.7 & 5.2 \\
\hline $13: 00-14: 00$ & 54.8 & 8.2 & 22.8 & 67.8 & 159.6 & 10.4 & 15.2 & 9.6 \\
\hline $14: 00-15: 00$ & 101.1 & 7.0 & 18.1 & 48.0 & 122.8 & 8.6 & 13.0 & 7.2 \\
\hline $15: 00-16: 00$ & 50.1 & 7.3 & 20.1 & 50.7 & 107.0 & 8.9 & 11.3 & 6.4 \\
\hline $16: 00-17: 00$ & 58.6 & 8.1 & 21.1 & 55.0 & 155.0 & 13.0 & 19.8 & 10.7 \\
\hline $17: 00-18: 00$ & 44.7 & 5.6 & 15.3 & 37.6 & 80.6 & 6.5 & 12.2 & 6.3 \\
\hline $18: 00-19: 00$ & 34.7 & 4.3 & 14.4 & 40.5 & 102.5 & 6.5 & 13.6 & 7.8 \\
\hline 19:00-20:00 & 112.0 & 8.8 & 29.5 & 64.9 & 102.6 & 5.9 & 8.9 & 5.0 \\
\hline $20: 00-21: 00$ & 38.7 & 6.9 & 18.4 & 46.1 & 89.2 & 5.0 & 10.5 & 6.3 \\
\hline $21: 00-22: 00$ & 45.6 & 7.0 & 19.5 & 49.2 & 108.3 & 8.1 & 15.6 & 8.2 \\
\hline $22: 00-23: 00$ & 48.1 & 7.3 & 20.1 & 50.7 & 127.0 & 11.9 & 21.3 & 12.4 \\
\hline $23: 00-24: 00$ & 33.4 & 6.2 & 17.7 & 48.7 & 139.6 & 10.6 & 19.1 & 10.9 \\
\hline
\end{tabular}

\section{References}

1. Li, Z.; Li, D.; Oh, J. R.; Je, J. G. Chemosphere 2004, 56, 611.

2. Wu, N.; Huang, H.; Zhang, S.; Zhu, Y. G.; Christie, P.; Zhang, Y. Environ. Pollut. 2009, 157, 1613.

3. Kim, S. K. Chemosphere 2012, 89, 995.

4. Lee, S.; Kim, B.; Kim, J. J. Chromatogr. A 2013, 1277, 35.

5. Ferrer, C.; Lozano, A.; Agüera, A.; Jiménez Girón, A.; FernándezAlba, A. R. J. Chromatogr. A 2012, 1218, 7634.

6. Kannan, N.; Petrick, G.; Bruhn, R.; Schulz-Bull, D. E. Chemosphere 1998, 37, 2385.

7. Primbs, T.; Piekarz, A.; Wilson, G.; Schmedding, D.; Higginbotham, C.; Field, J.; Simonich, S. M. Environ. Sci. Technol. 2008, 42, 6385.

8. Hayward, S. J.; Gouin, T.; Wania, F. Environ. Sci. Technol. 2010, 44,3410 .

9. Arinaitwe, K.; Kiremire, B. T.; Muir, D. C. G.; Fellin, P.; Li, H.; Teixeira, C.; Mubiru, D. N. Environ. Sci. Technol. 2012, 46, 11524.

10. Zhang, Z. L.; Zhou, J. L. J. Chromatogr. A 2007, 1154, 205.

11. Kannan, N.; Petrick, G.; Schultz-Bull, D. E.; Duinker, J. C. J. Chromatogr. A 1993, 642, 425.

12. Herrero, P.; Borrull, F.; Marcé, R. M.; Pocurull, E. J. Chromatogr. A 2013, 1285, 31.

13. Oellig, C.; Schwack, W. J. Chromatogr. A 2012, 1260, 42.

14. Choi, S. D.; Baek, S. Y.; Chang, Y. S. Atmos. Environ. 2008, 42,
2479.

15. Pereira, M. G.; Walker, L. A.; Wright, J.; Best, J.; Shore, R. F. Environ. Sci. Technol. 2009, 43, 9010.

16. Liu, S.; Tao, S.; Liu, W.; Liu, Y.; Dou, H.; Zhao, J.; Wang, L.; Wang, J.; Tian, Z.; Gao, Y. Environ. Sci. Technol. 2007, 41, 8256.

17. Lohmann, R.; Dapsis, M.; Morgan, E. J.; Dekany, V.; Luey, P. J. Environ. Sci. Technol. 2011, 45, 2655.

18. Sae-Khow, O.; Mitra, S. Anal. Chem. 2010, 82, 5561.

19. Saridara, C.; Ragunath, S.; Pu, Y.; Mitra, S. Anal. Chim. Acta 2012, 677, 50.

20. Sae-Khow, O.; Mitra, S. J. Chromatogr. A 2010, 1217, 2736.

21. Deng, X.; Xie, P.; Qi, M.; Liang, G.; Chen, J.; Ma, Z.; Jiang, Y. J. Chromatogr. A 2012, 1219, 75.

22. Preter, V. D.; Staeyen, G. V.; Esser, D.; Rutgeerts, P.; Verbeke, K. J. Chromatogr. A 2009, 1216, 1476.

23. Soria, A. C.; Martínez-Castro, I.; Sanz, J. J. Chromatogr. A 2009, $1216,3300$.

24. Lara-Gonzalo, A.; Sánchez-Uría, J. E.; Segovia-García, E.; SanzMedel, A. Talanta 2008, 74, 1455.

25. Yang, C.; Piao, X.; Qiu, J.; Wang, X.; Ren, C.; Li, D. J. Chromatogr. A 2011, $1218,1549$.

26. Li, D.; Yang, C.; Ren, C. China Patent ZL 200820071370.4, 2008.

27. Yang, C.; Qiu, J.; Ren, C.; Piao, X.; Li, X.; Wu, X.; Li, D. J. Chromatogr. A 2009, 1216, 7694. 